\title{
Study on the Guidance Consultants' Training Needs, Based on the 'Support Plan for Socially Vulnerable Groups' in Greece
}

\author{
Kyriaki Papadaki* \& Argyris Kyridis ${ }^{1 *}$ \\ *Department of Early Childhood, University of Western Macedonia \\ Ikoniou 2, GR-582 00, Edessa, Pella, Greece \\ Tel: 30-694-452-9834 E-mail: kpapadaki@gmail.com \\ ${ }^{1 * D e p a r t m e n t}$ of Early Childhood Education, Aristotle University of Thessaloniki, Greece \\ E-mail:akiridis@nured.auth.gr
}

Received: January 10, 2012 Accepted: March 19, 2012 Published: June 25, 2012

doi:10.5296/ije.v4i2.1993 URL: http://dx.doi.org/10.5296/ije.v4i2.1993

\begin{abstract}
The present study attempts to investigate the training needs (in terms of guidance, methodology, responsiveness to specific group - target) of Vocational Consulting, who worked in the "Plan Support of Socially Vulnerable Groups," held by the Prefectural Committee for Adult Education (NELE) Larissa from September 2006 until September 2008. Firstly, it investigates the knowledge of the Executive Advisory body to the meaning and role of the Advisory as a science. Subsequently, it investigates the awareness of training needs specifying areas and linking those needs with the requirements of the group and the target which is supported. The analysis of the results and their connection to the research questions suggests that the Consultants consider their role especially important, realizing the essence and importance of the process and, moreover, that a further training in counselling skills is needed. This is a view expressed both by the most experienced executives, who have been involved in the process of training at least once, and the younger executives, who have not ever attended a training program in counselling.
\end{abstract}

Keywords: counselling, vocational guidance; vulnerable social groups; managers of counselling; educational needs; adult education; training; departmental committee on adult education 


\section{Introduction}

Our era is characterized by complexity and rapid change. The modern man is called to produce a highly competitive work in an evolving world. This situation often creates high anxiety to people. The role of the Advisory is very necessary, in all aspects of life and for all population groups, vulnerable or not.

The present study attempts to investigate the training needs (in terms of guidance, methodology, responsiveness to specific group - target) of Vocational Consulting, who worked in the "Plan Support of Socially Vulnerable Groups," held by the Prefectural Committee for Adult Education (NELE) of Larissa from September 2006 until September 2008.

Firstly, it investigated the knowledge of the Executive Advisory body to the meaning and role of the Advisory as a science. Then, it investigates the awareness of training needs, specifying areas and linking those needs with the requirements of the group - target which is supported.

This survey is consisted by three parts. The first refers to the definition of the terms Guidance, Counselling and Vulnerable groups. It is clear that the term of counselling involves a range of definitions which enable us to realize that this science is wide. The recipients of the consultative process may seek two basic types of counseling. The first is the Educational Counselling, and the second the Vocational. The first regards the assistance for education and study, while the second that for employment.

The Consultative process is supported, to a large extent, on the success of the Executive who offers his services in a program. The activity does not depend solely on his training in certain techniques or on his specific scientific expertise, but on his sensitivity to the needs of the person standing opposite to him as well. The first essential step for the successful outcome of this consultative process is the relationship between the two sides. There is a kind of confusion around the goals put through in the process of counselling, regarding the view that the consultative process focuses on particular fields of man's life without taking into account the general culture of his life, or, around the conception that the counselling is completed when just having taken a decision without seeking for feedback.

The advisory process is necessary to both the general population and people belonging to vulnerable social groups. When an Executive will be asked to support socially vulnerable people he needs to develop further professional knowledge and skills to meet the particularities of each group. In the field of education and educational programs for adults, the primary step is to investigate the range of needs.

This process of investigating the educational needs presents several difficulties; however, there are two components, which should be given essential special attention during this process. One is the frame of reference and the second is the population - target.

The design and implementation of this research was based on the study of bibliography on the Advisory science, the methodology for investigating teaching and research needs, in general. In this perspective, it defined its purpose, formulated research questions and selected the methodology. 


\section{Defining terms}

Based on the exploration of the systems of Career Guidance in Europe and worldwide, the OECD (2004.19) formulates a multidimensional lifelong definition of career guidance:

"Career guidance refers to services designed to help people of any and at any stage of their lives, to get educational and occupational decisions and manage their careers....Helps people to reflect the aspirations, interests, skills and abilities....Contributes to the understanding of education and the labor market and linking the relationship of this knowledge to what people know about themselves....Teaches people to plan and make decisions about work and learning....Makes information on the labor market and educational opportunities more accessible, when and where people in need seek for, through better organization and systematization..." (Papavassiliou, 2006).

A simple and general definition that could be formulated to describe the counselling is the assistance to the Director in offering consulting on an issue to the person that needs it and that employs him and whose decision is solely the responsibility of the second one (Papatheofilou, Sakkas \& Polemi - Todoulou, 1994). This definition is very wide and rather minimally descriptive on the Counselling (Arnold, 1962).

An alternative definition for Counselling refers to the Glossary of Terms Accreditation (2007), National Centre for Continuing Vocational Training, under which: "... The scientific help and support given to people is based on this methodology to identify and succeed personal and professional goals."

\section{Counselling}

\subsection{Educational Counselling}

The Educational Counseling is widespread nowadays. For this reason, an increasing number of counseling psychologists work in higher education with the aim to teach psychology and to counsel psychology as well as to develop researches. The teaching duties of these trainers may include (Lucas, Blazek, \& Raley, 2005):

-The advanced education for students of psychology courses in counseling psychology.

-The introduction of theory and practice of counseling psychology to students on relevant courses (such as social work and psychology).

-The teaching of counseling skills to Health professionals (e.g. doctors, nurses, physiotherapists).

-The teaching-management and consultancy skills to students and colleagues from a range of undergraduate and postgraduate courses.

-The teaching of counseling skills to police officers, fire officers and staff ambulances. 
As mentioned by Blocher (1966) one of the distinguishing characteristics of the professional who exercises Educational Consulting is that, simultaneously, he uses different roles and to varying degrees, even when working with people with serious problems.

\subsection{Professional Counseling for Adults}

On the other hand, Professional Counseling for adults refers to the assistance offered by a specialist to people with questions about their careers (Dowing, 1975). To help these people solve their business issues, it is necessary to have an awareness of their overall situation, focusing on issues that concern their personal life (Nathan \& Hill, 2006). It is clear that to allow the adult to accept help and counseling, there should be an overview of his peculiarities.

Vocational decisions can not be taken independently to other decisions affecting a person (Pieck, 2005). This is easily understood when one considers how a decision affects the nature of his professional time or the nature of his social relationships created during the day (Amundson et al., 2008). That is the inextricable link between the issues in the professional field and those listed in the personal life of the man involved in general psychology. This is something that should always be taken seriously into account, within the framework of a vocational counseling process.

On this basis, during the meeting between a specialized consultant and an individual or a group of people, it is planned the educational and / or the career path of those who are concerned and involved. This course does not finish once and for all, for example when making specific individual educational / professional decisions, but is a lifelong process with stages, changes and effects of various psychological and environmental factors (Bennell, 1999).

The Professional Counseling, based on two-way inter-speech and equal communication between both the consultant and beneficiary, focuses on three interdependent pillars: self-knowledge, information and decision (Dempster, 1989). More specifically, the sessions of this nature can be devoted to explore the interests, inclinations, skills, motivation or values of an individual, e.g. components of his self-knowledge, but also the necessary skills to help training him to "survive" in labor market. Furthermore, it is appropriate to consider the information related to educational / work environment, such as curriculum guidelines, the prospects of various occupations, new forms of industrial relations, political reforms, etc. All the above information which either makes up the profile of consulting (self-knowledge) or derive from the context in which he operates (knowledge of his environment), are combined and evaluated to lead to a decision. The selection and development of educational / vocational course is the target between the consultant and the person in his need.(Kakarouha, 2005).

In summary, Professional Counseling, being in line with the general developments in entrepreneurship and overall professional rehabilitation, has a holistic approach to the requests of people in need of support, uses various media, and contributes to the enhancement of business spirit (Woolfolk, Winne \& Perry, 2006). The aim of Professional Counseling is to give emphasis to the personality of the recipient of any advice, to assess his readiness to undertake entrepreneurial activity and generally join in the area of labor market, as well as to the characteristics of the environment which may determine the degree of success (Hayes \& Hobson, 1981). 
The consultative process could be attributed to the following chart:

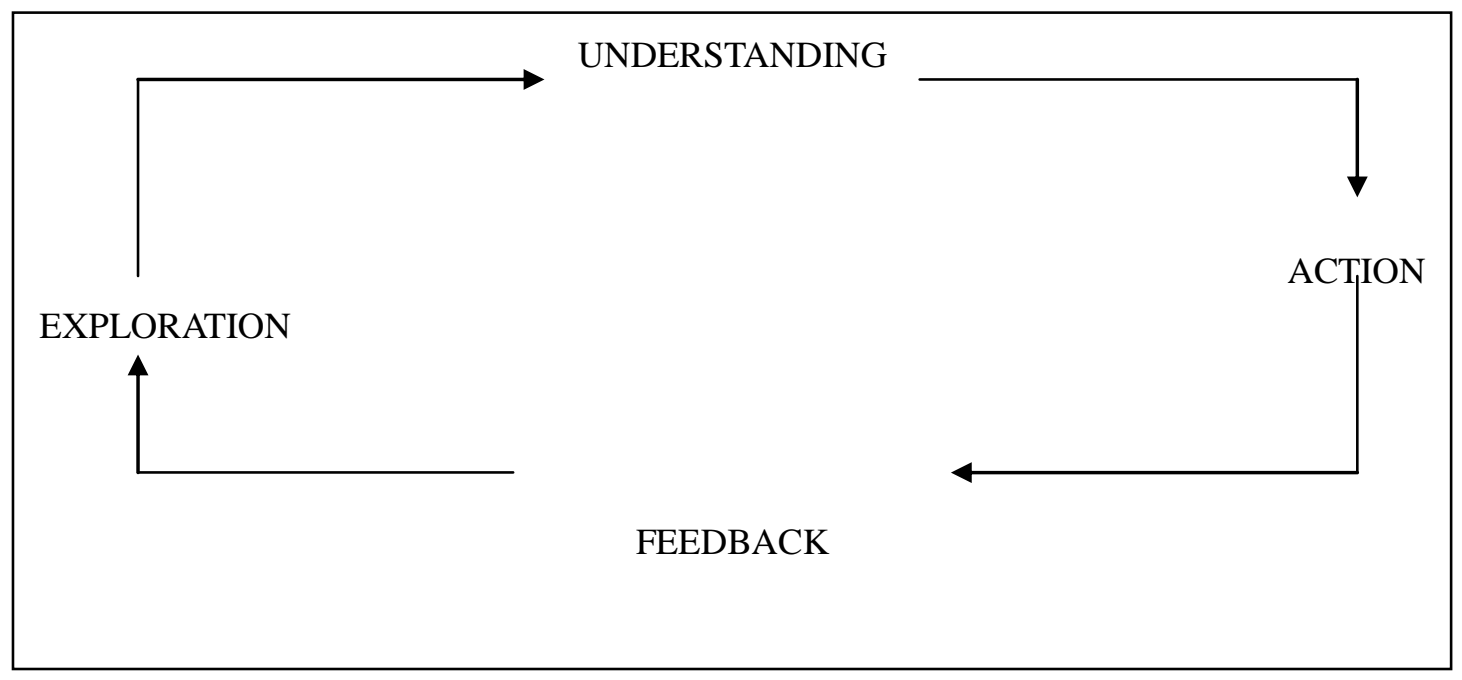

Figure 1: Phases of consulting Process

\subsection{Consulting Vulnerable Social Groups}

\subsubsection{Consulting Support Services}

Bloom (2005) mentioned the advisory process is an entirely necessary need, which is provided to both the general vulnerable population and those who belong to the special vulnerable social groups. These people, because of the difficulties they face on the conditions and circumstances of life, are called to face additional difficulties of integration or re-integration into family, educational, professional, friendly or wider society (Papantoniou, 2007). The more features and differences one may have in relation to what is now regarded by society as "normal" and acceptable, the more difficult is the smooth integration into this society (Levitas, 1998). Immediate consequence of that is the existence of even greater need for effort in this direction of integration.

The need for this adaptation of vulnerable people in «normal» society led to the development and design of Accompanying Supporting Services (ASS) from the perspective of social actors and constitutions (Tsapournas, 2008). The effect of ASS on either the same people or vulnerable groups at risk of social exclusion, or wider society within which is lived develops this phenomenon. In the first case, it is attempted to animate a multifaceted support of socially vulnerable individuals or groups in order to smooth their integration into society on their own needs or abilities observed. Similarly, the second is to attempt preparing the society to try to integrate and assimilate as equal the members of vulnerable social groups (Dimitropoulos, Apostle).

\subsubsection{The role and characteristics of the Consulting Executive at vulnerable social groups}

When a Consulting Executive will address support to socially vulnerable individuals or groups, he must further develop professional knowledge and skills that are not easily grouped together, and vary depending on the particularities of each group. In any case, it is considered 
essential and required knowledge, by the Consulting Staff, of the characteristics of beneficiaries who will be supported through the Advisory. In this way, they manage to successfully cope with multiculturalism of the information they meet (Amundson et al., 2008). Of course, multiculturalism is not an exclusive characteristic of socially vulnerable groups. In these special circumstances however, it is highly needed by the shaft to show even greater attention to management.

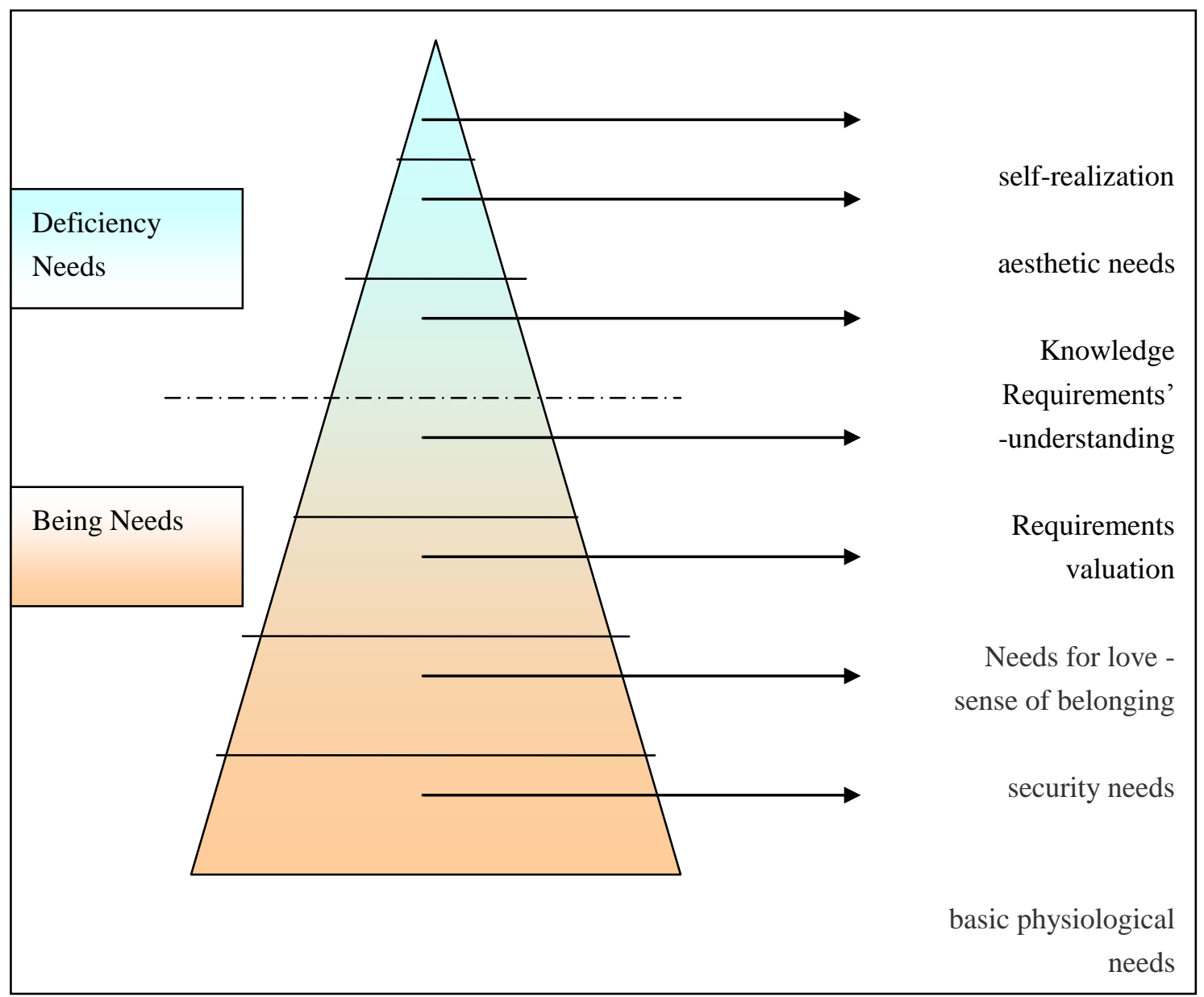

Figure 2: Maslow's hierarchy of needs' pyramid (Kedraka, 2007)

The concept of acceptance and support plays important role in the process of counseling people of vulnerable social groups. Admission is absolutely important to support these individuals, as directly related to the self-esteem which is developed (Kleftaras, 2004). In general, the empowerment, support and aid, when based on specific needs and special skills of the beneficiaries, are the main duties of the Executives of vulnerable social groups and lead to the inclusion of all in society on equal terms (Zannas, Blairon).

According to Maslow (1970) everyone travels the stage realization of basic needs, after having met only a degree needs to proceed to the next one. However, if we do not need to emerge the highest level, this may mean that one of the lowest levels of needs is not met adequately. Regarding the developmental needs and particularly the level of self-actualization, Maslow's view is that possibly it is not accessed by all human beings (Rogers, 1999). 


\section{Mll Macrothink}

\section{Needs and labor market}

Of course, the educational needs relate to each other and as directly to the situation on the labor market (Pieck, 2005). It can not be denied that a key part of educational needs has to do with the need to absorb the labor market (Siamopoulos, 2006). Specifically, in identifying needs in the labor market, it is supported: "We must recognize that there is a valid method for predicting the demand for skilled workforce". "However, some empirical methods are used for determining the labor market from which the most useful seem to be the following (Flint, 1999):
A. The sectored approach
B. The collection and processing of data on vacancies
C. The investigation of local labor market
D. The consultation procedures,

As shown above, investigating the educational needs of the labor market is a complex process. For this reason, there is a high risk to lead to distorted conclusions, if we keep limiting it to statistical analysis of responses of a questionnaire or a simple selection of topics by an adult on the list in a sample survey.

\section{General Information for Research}

\subsection{Aim}

The basic objective of this study is to provide a comprehensive, authoritative and recent picture of the knowledge of the Management of Counseling on the meaning and the role of the Advisory Science (Prefectural Committees of Adult Education, Larissa) and to investigate the training needs of the Executives themselves in relation to the group - target support.

\subsection{Research questions}

The study of bibliography combined with personal experience directed to formulate the following research questions:

- The Executives know the meaning and the role of the Advisory Commission as a science?

- The Executives believe that they need further training in counselling?

- Are they related to the educational needs of the Executive Advisory team -target of consulting adults whom they are invited to support?

\subsection{Methodology of the survey}

\subsubsection{The sample}

Participants were not selected at random sample, and, in fact, their number was small. Therefore, in order the answers to be sufficient and to meet the goals of the research effort, there had been an effort to give interviews to all Executives who worked on this project. It is urgent to mention that none of the people participated on the survey had a permanent 
employment relationship with the body work, but cooperation was in the context of this project.

Specifically, the sample consisted of 20 Executives in Consulting, 15 of which were women $(75 \%)$ and 5 were men $(25 \%)$. Of all the participants in the study, $3(15 \%)$ were holders of Technological Educational Institute (TEI) and 17 (85\%) were University Graduates. Of the graduates TEI none $(0 \%)$ was not an MBA, while 9 people $(45 \%)$ from university graduates had master's degrees and $2(10 \%)$ had a doctorate. Regarding the type of study, $17(85 \%)$ Executives were from the field of humanities - social sciences, 2 (10\%) from the field of business administration and $1(5 \%)$ from the field of positive sciences. As for the experience on the Vocational Counseling on advising programs, there is a variation from 2 to 17 years.

\subsubsection{Research tool to collect data}

The survey was carried out based on the model of quality approach, which enables deeper analysis and interpretation of facts, knowledge-term and needs (Room, 1995). The research technique - method used was that of a structured interview with mainly open-ended questions. This method was chosen by the researcher as the safest technique for collecting data for this study. The reasons that contributed to the selection of structured interview was both the awareness of the small sample numbers of respondents thus the need to ensure the collection of specific information that would answer the purpose of research.

Through individual structured interviews it was explored the knowledge of Management Advisory on the meaning and role of consultative environmental science, and to identify their needs for training in specific menu item, attempting to associate it with the group - target they supported.

The axes of the interviews were crystallized into after pilot testing and discussion with 5 of the participants (25\% of the total sample rate). The answers were given by each interviewee, both during the pilot and the normal course of the investigation, and were confidential secret in the sense that the name was not recorded.However, the interviewer recorded each answer on a specially constructed list containing the axes of the interview and specific questions were posed to explore.

The interview was held with axes of 12 questions, which are found in the Appendix. Before the basic questions (lines), prior to 5 preliminary questions, it was investigated the demographics, qualifications and profile of the Executive (experience on consulting support, type and level of education, previous training in advisory).

\subsubsection{The questions}

- The questions 1-6 investigated the knowledge of Management counseling on the meaning and role of the Advisory Science (posing definitions of consulting, determining the role in programs support, recognition of the needs that lead people to request support and guidance, significance of opening meeting, making way for the Advisory proceedings).

-The questions 7, 8 and 9 investigated: a) the need for further training for Executives b) the 


\section{Macrothink}

reasons that lead to extra training and c) identify areas where's need for training.

- The questions 10, 11 and 12 investigated the correlation observed between the need for training and the support of specific vulnerable groups.

At the end of the interview each participant was able to formulate freely any comments regarding the content of the interview.

\subsection{Process of research}

The survey was conducted during the academic year 2008 to 2009. The bibliography research, the recording of the objective and research questions were held from October 2008 until the February 2009, while the implementation of research through the construction of research tool, the collection and processing of data were held between March and May 2009.

Regarding the responses of all respondents, it is considered to be useful to draw up a list of the basic keys, which yielded the most powerful correspondence to concepts - key definitions assigned from time to time in the bibliography.

Table 1: Keywords for defining Guidance

\begin{tabular}{lll}
\hline keywords & to describe & Science consulting \\
\hline Support & Acceptance & Confidence \\
Animation & Respect & Investigation skills \\
Guidance & Crisis & Empowerment \\
Labor issues & Enhancing confidence & Professional rehabilitation \\
Educational issues & Decision & Help \\
Mobilization & Investigation needs & Update information \\
Developing self-awareness & Processing problems & Personal development \\
Social inclusion & Simultaneous & Encouraging \\
& consideration of issues & \\
Vocational guidance & Hint options & Improving interpersonal relations \\
\hline
\end{tabular}

According to the replies given in the second part of questions, it is showed that $25 \%$ of respondents believe that there is no differentiation between their roles as Executives Consultants of general population and vulnerable social groups, while $75 \%$ believe that there is, indeed, a significant difference.

\section{Presentation and analysis of results}

What we mostly conclude from the study and treatment of participants' responses to the survey is that the main reasons that motivate people to participate in a consulting supportive program are primarily listed into the following categories:

1) Social and psychological support

2) Job search techniques and vocational rehabilitation

3) Vocational guidance and information on labor issues 
4) Enhance self-confidence

5) Resocialisation for specific vulnerable groups such as roma, immigrants and prisoners

6) Handling personal problems

7) Guidance in decision making

8) Need for acceptance

9) Financial aid and support

10) Business support

As highlighted by one of the interviews given by Executives:

"The beneficiaries who attend counseling sessions in order to be accepted by the Staff, expressing freely their concerns and taking specific support issues that lead them to the program, ... feel the need to be addressed with respect to their personality and culture (especially when it comes to socially vulnerable groups) and to receive the maximum possible training and information to help achieve their goals ".

The table below indicates the stages included in the opening meeting, according to the answers of the people and organizations who conducted these meetings (the Executives).

Table 2.

\begin{tabular}{lcc}
\hline \multicolumn{1}{c}{ Stages of opening meeting } & Total answers & Percentage \\
\hline Acquaintance with the beneficiaries & 20 & $100 \%$ \\
Convey Consulting & 20 & $100 \%$ \\
Contract & 20 & $100 \%$ \\
Diagnosis of the needs for the counseling & 20 & $100 \%$ \\
Creating a mutual trust relationship between the two & & \\
sides & 20 & $100 \%$ \\
Information about the program & 20 & $100 \%$ \\
Referral to professionals responsible for matters & & $100 \%$ \\
relating to consulting & 20 & \\
Create a profile of beneficiaries & &
\end{tabular}

Table 3.

\begin{tabular}{lcc}
\hline Get professional decision & Answers & Percentage \\
\hline In line with the rest of his life & 17 & $85 \%$ \\
Regardless to the rest of life & 3 & $15 \%$ \\
Total answers & 20 & $100 \%$ \\
\hline
\end{tabular}

From the above table it can be concluded that the participants in research at a rate of $85 \%$ declare themselves to take a vocational decision required with review of other factors in life. On the other hand, there is a smaller percentage, which reaches $15 \%$ of respondents, stating 
that vocational decisions should be taken individually and independently from their other activities and events of the life.

The Executives, regardless of their profile, show to realize in a large extent the fact that professional decisions can not be considered and taken without consideration of the factors related to personal life.

Indicative is the answer of one of the respondents:

"In order to take a professional decision (joined in Consultative process) it is best to take into account the entire life of the beneficiaries, such as past experiences and the experiences of professional or ex-educational level, the social and economic background. The failure to take into account these factors may lead to a seemingly good decision, which seems to have a positive outlook for the recipient, but, ultimately the goal is difficult to achieve. This is why a decision taken in this way can not leave uninfluenced the other aspects of life and activities of individuals, which are not counted from the beginning ..."

At this point it is worth mentioning 2 views of people who are fans of this perception:

"... No Counseling Executive, no matter how experienced and specialized knowledge achieved he has accomplished, even if available, cannot be considered to be absolutely true to his crisis and that he will decide the best course for the consulting. The purpose of counselling should be a common effort between the executive and the beneficiary to the consulting for the second's autonomy and his encouragement for active participation in making decisions to solve the issues that concern him".

"...the Role of the Counseling Executive is not to make decisions for the beneficiaries' part, but to facilitate and guide them so that they can find the best options through which they will improve the quality of their lives ..."

Typical is the view expressed by one interviewee who among other answers stated that:

"... The role of Executive Advisory is highly active in the consulting. Thus, the decision in favor of beneficiaries shows the strong interest in helping and supporting people in need ..."

The response options given in twenty respondents were:

- Answer choice A: Particular target group

Answer choice B: Ability to acquire specialized knowledge

- Answer choice C: Training in the use of tools advisory harmonized the modern needs of beneficiaries

- Answer choice D: Guidance on new technical advisory harmonized the modern needs of beneficiaries 
- Answer choice E: Find ways of networking with other Executives and local community

Table 4.

\begin{tabular}{|c|c|c|c|c|c|}
\hline Row of executive & Answer A & Answer B & Answer C & Answer D & Answer $\mathrm{E}$ \\
\hline $1^{\text {st }}$ & $x$ & $x$ & $\mathrm{x}$ & $x$ & $x$ \\
\hline $2^{\text {nd }}$ & & $x$ & $x$ & & \\
\hline $3^{\text {rd }}$ & $x$ & & $x$ & $x$ & $x$ \\
\hline $4^{\text {th }}$ & $x$ & $x$ & $x$ & $x$ & $x$ \\
\hline $5^{\text {th }}$ & $x$ & $x$ & $x$ & $x$ & $x$ \\
\hline $6^{\text {th }}$ & & $x$ & $x$ & $x$ & \\
\hline $7^{\text {th }}$ & & $x$ & & & \\
\hline $8^{\text {th }}$ & $x$ & $x$ & $x$ & $x$ & \\
\hline $9^{\text {th }}$ & & & $x$ & $x$ & $x$ \\
\hline $10^{\text {th }}$ & & $x$ & $x$ & $x$ & $x$ \\
\hline $11^{\text {th }}$ & $x$ & $x$ & & $x$ & \\
\hline $12^{\text {th }}$ & $x$ & $x$ & $x$ & $x$ & $x$ \\
\hline $13^{\text {th }}$ & $x$ & & $x$ & $x$ & \\
\hline $14^{\text {th }}$ & $x$ & & & & \\
\hline $15^{\text {th }}$ & $x$ & $x$ & $x$ & $x$ & $x$ \\
\hline $16^{\text {th }}$ & $x$ & $x$ & $x$ & $x$ & \\
\hline $17^{\text {th }}$ & $x$ & $x$ & $x$ & $x$ & $x$ \\
\hline $18^{\text {th }}$ & $x$ & $x$ & & $x$ & $x$ \\
\hline $19^{\text {th }}$ & & $x$ & $x$ & $x$ & \\
\hline $20^{\text {th }}$ & $x$ & $x$ & $x$ & $x$ & $x$ \\
\hline TOTAL & 14 & 16 & 16 & 17 & 11 \\
\hline PERCENTAGE & $70 \%$ & $80 \%$ & $80 \%$ & $85 \%$ & $55 \%$ \\
\hline
\end{tabular}


Table 5.

Row of

executive

A

B $\quad$ X

$\begin{array}{ll}C & D \\ X & X\end{array}$

E

$\mathrm{F}$

G

Answer of

executive

$1^{\text {st }}$

$2^{\text {nd }}$

$3^{\text {rd }}$

$4^{\text {th }}$

$5^{\text {th }}$

$6^{\text {th }}$

$7^{\text {th }}$

$8^{\text {th }}$

$9^{\text {th }}$

$10^{\text {th }}$

$11^{\text {th }}$

$12^{\text {th }}$

$13^{\text {th }}$

$14^{\text {th }}$

$15^{\text {th }}$

$16^{\text {th }}$

$17^{\text {th }}$

$18^{\text {th }}$

$19^{\text {th }}$

$20^{\text {th }}$

TOTAL

$\begin{array}{lll}x & x & x \\ x & x & x \\ & x & x\end{array}$

$\begin{array}{llllll} & x & & x & & \\ x & x & x & & & \\ x & x & x & x & x & x \\ x & x & x & x & x & x\end{array}$

$x$

$x$

$x \quad x$

$x$

$x$

$$
x
$$

$x$
$x$

$x$

$x$

$x$

$x$

$x$
$x \quad x$

$x$

$x$

$x$

$\mathrm{X}$

$x$

PERCENTAGE 
Table 6.

\begin{tabular}{|c|c|c|c|c|c|c|c|}
\hline \multicolumn{8}{|l|}{ Row of executive } \\
\hline & A & B & C & D & E & $\mathbf{F}$ & $\mathbf{G}$ \\
\hline $1^{\text {st }}$ & & & $x$ & $x$ & $x$ & & $x$ \\
\hline $2^{\text {nd }}$ & $x$ & $x$ & $x$ & $x$ & $x$ & $x$ & $x$ \\
\hline $3^{\text {rd }}$ & $x$ & $x$ & $x$ & $x$ & $x$ & $x$ & $x$ \\
\hline $4^{\text {th }}$ & & $x$ & $x$ & & & $x$ & \\
\hline $5^{\text {th }}$ & & & $x$ & & & & $x$ \\
\hline $6^{\text {th }}$ & & $x$ & & & & & \\
\hline $7^{\text {th }}$ & $x$ & $x$ & $x$ & $x$ & $x$ & $x$ & $x$ \\
\hline $8^{\text {th }}$ & $x$ & & & $x$ & & $x$ & \\
\hline $9^{\text {th }}$ & $x$ & $x$ & $x$ & $x$ & $x$ & $x$ & $x$ \\
\hline $10^{\text {th }}$ & & $x$ & $x$ & & & $x$ & $x$ \\
\hline $11^{\text {th }}$ & $x$ & $x$ & $x$ & $x$ & $x$ & $x$ & $x$ \\
\hline $12^{\text {th }}$ & & $x$ & & & & & \\
\hline $13^{\text {th }}$ & & & $x$ & & & & \\
\hline $14^{\text {th }}$ & & & $x$ & & & & \\
\hline $15^{\text {th }}$ & $x$ & $x$ & $x$ & $x$ & $x$ & $x$ & $x$ \\
\hline $16^{\text {th }}$ & & $x$ & $x$ & $x$ & & $x$ & \\
\hline $17^{\text {th }}$ & & $x$ & $x$ & $x$ & & & \\
\hline $18^{\text {th }}$ & & $x$ & & $x$ & & $x$ & \\
\hline $19^{\text {th }}$ & & $x$ & $x$ & $x$ & & & \\
\hline $20^{\text {th }}$ & $x$ & $x$ & $x$ & $x$ & $x$ & $x$ & $x$ \\
\hline TOTAL & 8 & 15 & 16 & 13 & 8 & 12 & 10 \\
\hline PERCENTAGE & $40 \%$ & $75 \%$ & $80 \%$ & $65 \%$ & $40 \%$ & $60 \%$ & $50 \%$ \\
\hline
\end{tabular}

\section{Conclusion}

Summarizing what can be said is that the Executives have to face difficulties which emerge from society's disresponse to consulting (vulnerable social groups or not), the ineffectiveness of vocational rehabilitation and the lack of theory and empirical research on the most appropriate method that should be followed every time. Therefore, the Executives must improvise to keep abreast of market needs, attitudes of employers, workers and society.

Moreover, it is absolutely necessary for the Executives to know the peculiarities of each vulnerable group - target that should be supported, so to study the personality of their beneficiaries, beginning by exploring their needs and, finally, to mobilize all available support networks. The ultimate goal is not only growing their vocational skills, but also changing their lifestyle (Bennell, 1999).

The Executive must retain data on the attempts made by his beneficiaries to guide, provide questionnaires to determine their needs or the causes that are responsible for their, up to now, failure in professional or personal level. Consequently, the Executive may not be a person who simply has a degree in psychology, sociology or social work. Instead, he will 
have a graduate degree in consulting or specialized training in counselling socially vulnerable groups.

From the analysis of the results and their connection to the research questions it is obvious that the Executives entirely consider their role especially important, realizing the essence and importance of the process and, moreover, that a further training in counseling skills is needed. This is a view expressed both by the most experienced executives, who have been involved in the process of training at least once, and the younger executives, who have not ever attended a training program before.

In particular, the clear knowledge of the Executive on the meaning and role of his Science lies in the definition to define the role of equity in programs, in recognition of the needs that lead people to seek help or guidance and the importance attached to the first Consultative Meeting.

More specifically, in their entirety majority, Executives define counselling as the process of diagnosing needs, empowerment, mentoring, and examining issues regarding personal and professional fields, educational concerns by the beneficiaries but also as a process to demand solutions to potential benefits for them. Additionally, it is generally accepted that a vocational decision in the consultative process can not be considered separately from other aspects of peoples' lives.

Regarding the role played by each Executive observed, there is a general stated opinion, indicating that the main concern is to encourage beneficiaries to express issues of concern to their employment, then to help them understand themselves better, to seek and provide with information about possible solutions that meet their desires. Generally, it is to support the person in his efforts to make changes in his life to get improvement. However, there were beliefs (a small percentage) according to which the Executives misinterpreted their role in supporting in a way that, among their duties, it is to include the responsibility of making a decision in favor of the person.

Regarding the issue of the assessment of those needs that lead people to participate in a counseling program, the views expressed follow: The challenge for beneficiaries is the psychological and social support to pass through the impasse that has arrived, whether it is vocational or family, or any other of their lives. In addition, to boost their self-esteem, learn about job searching techniques and focus or redirect profession. Especially when it comes to socially vulnerable groups' needs, the main focus lies on integration or reintegration into society.

About the importance of the opening meeting in a Consulting program, all Executives clearly state that this is the most important of all the meetings. This is apparent from respondents' answers that during the first meeting of the consult process the relationship can be built between the two sides and both can deal on the contract, which defines and frames the entire program. The opening meeting is to consider, to a fairly large extent, the course of other meetings as the Executive is able to determine the needs of the people he will support but the beneficiaries, on their side, have the opportunity to resolve any questions they have on 
the program.

On the issue of the necessity of extra training, it's found that all Executives recognize their need for further participation in educational programs. So, regardless of previous training or not, years of experience, type of degree (universities, technical colleges), possession or not of master or doctoral degree, in their entirety, the respondents expressed a desire to be engaged in a process of education in Counselling. They claim as imperative need getting expertise training when called upon to support socially vulnerable groups, which require specialized handling because of their specific features.

Specifically, the areas where the Executives believe they need further training are summarized as below. Knowledge of the law related to counselling socially vulnerable groups according to the latest developments occurring in this area. Management of the procedures of unforeseen situations in the process of conducting a counseling session. Education and career issues of behavior but as well the understanding the personality of those belonging to vulnerable social groups. Using modern tools and techniques for job searching in coherence of needs created by today's living conditions to people of general population, but also socially vulnerable groups. Expertise for guidance in the decision making process and, finally, find ways of establishing a network of cooperation and mutual assistance with both the local community and the labor market, and the other Executives active promoters in their respective programs.

The reasons why the Executives interviewed are forced to express their need for further training in counselling stem from the inability they feel to one or more of the areas mentioned above. As for the groups - targets which are considered to have more demands on the part of the Executive, particular reference was for those in prison (due to confinement), gypsies (due to different cultures) and disability (due to physical or mental difficulties when socializing) because the specificities of these groups experience much more intense.

\section{References}

Amundson, N., Harris - Bowlsbey, J., \& Niles, S. (2008). Principles of Professional Counselling, Procedures and Techniques. Ohio: Pearson.

Argyle, M. (1972). The Social Psychology of Work. London: The Penguin Press

Arnold, D.L. (1962). Counselor Education as Responsible Self-Development. Counselor $\begin{array}{llll}\text { Education } \quad \text { and } \quad \text { Supervision, } & 1, & 1962, & 185-192 .\end{array}$ http://dx.doi.org/10.1002/j.1556-6978.1962.tb00348.x

Bennell, P. (1999). Learning to Change: Skills development among the economically vulnerable and socially excluded developing countries. Geneva: ILO

Blocher, D.E. (1966). Development Counseling. N.Y.: Ronald Press

Cohen, L., \& Manion, L. (1994). Educational Research Methodology. Athens: Me-taichmio. 
Dempster, F. N. (1989). Spacing effects and their implications for theory and practice. Educational Psychology Review, 1(4), 309-330. http://dx.doi.org/10.1007/BF01320097

Dimitropoulos, A., \& Apostolou, M. (nd). Philosophy and the wider context of the Organization Accompanying Support Services. Chapter 3. under the Project Development Training Material for the Training of Executives S.S., Training Management Trainers S.S. Evaluation and Certification Committee Executive S.S.

Dowing, L.N. (1975). Counseling Theories and Techniques. Chicago: Nelson-Hall

Flint, Thomas A., \& Associates. (1999). Best Practices in Adult Learning: A CAEL/APQC Benchmarking Study. New York: Forbes Custom Publishing

Flint, Thomas A. (1999). Loan-Leveraged Learning: When Employer Tuition Aid isn't enough. CAEL Forum and News, 22(2), pp. 21-22, 42.

Georgiou, S. (2003). Training psychologists in counseling. Athens: Ellinika Grammata.

Georgiou, S. (2003).Training psychologists in counseling. Athens: Ellinika Grammata.

Gibson, R., \& Mitchell, M. (1986). Introduction to counseling and guidance. N.Y.: MacMillan.

Hayes, I \& Hobson, B. (1981). Careers guidance. Great Britain: Chaucer Press.

Kakarouhas, P. (2005). The Contribution of Vocational Counseling in Promotion of Entrepreneurship. Proceedings of 2nd Workshop Entrepreneurship Harokopeio University. Retrieved from: http://kallithea.hua.gr/epixeirein/index.htm

Kedraka, A. (2007). The Supporting of People who have abandonned education. Guide to Professional Advisory / a Youth Council. Project "On wheels: Next stop, the labor market." Community Initiative EQUAL, Pillar 1: Employability, Measure 1.1. Facilitating access and return to the labor market.

Kleftaras, G. (2004). The Body Image and Meaning in Psychological Counseling People with Physical Defects. Review of Counseling and Guidance, 68-69, 43-64.

Levitas, R. (1998). The inclusive society? Social exclusion and New Labour. Basingstoke: Macmillan.

Maslow, A.H. (1970). Motivation and personality. N.Y.: Harper \& Row

Nathan, R., \& Hill, L. (2006). Professional Counseling. The pre-Consultative approach of Vocational Choice and Career. London: Routledge.

OECD / European Commission (2004). Career Guidance. A handbook for Policy Makers, Paris: OECD Publications.OECD. (2004). Career Guidance and Public Policy, Bridging the Gap. Paris: OECD Publications.

Papantoniou, A. (2007). Educational and career choices of people at risk of social exclusion. Journal of Counseling and Guidance, 80 - 81, 215 - 230. Athens: Ellinika Grammata. 


\section{Macrothink}

International Journal of Education

ISSN 1948-5476

2012, Vol. 4, No. 2

Papatheofilou, R., Sakkas, D., \&War - Todoulou, M. (Ed). (1994). Interprofessional Advisory. Athens: Ellinika Grammata

Papavasiliou - Alexiou, J. (2006). Adult Career Counseling: Operation - Key to Education and Employment. Proceedings of the National Conference of Lifelong Learning to develop employment and social cohesion, 291-295.

Pieck, E. (2005). Work-related adult education: challenges and possibilities in poverty areas. International Journal of Lifelong education 24(5), 419-429. Mexico: Universidad Iberoamericana. http://dx.doi.org/10.1080/02601370500169798

Room, G. (1995). Beyond the Threshold: The Measurement and Analysis of Social Exclusion. Bristol: Policy Press.

Siamopoulos, D. (2006). The Role of the National Centre of Certification in the new era. Katartizein, 11, 2-3

Tsapournas, K. (2008). Career Guidance for Deaf or hard hearing Journal of Counseling and Guidance, 82 - 83, 214 - 224. Athens: Ellinika Grammata

Woolfolk, A. E.,Winne,P. H., \& Perry, N. E. (2006). Educational Psychology. Toronto, Canada: Pearson.

Zannos, P. \& Blairon, J.(n.d). Environment Development and Provision of Accompanying Support Services. Providers S.S. and Networks, Chapter 7. under the Project Development Training Material for the Training of Executives S.S., Training Management Trainers S.S. Evaluation and Certification Committee Executive S.S. 


\section{MlMacrothink}

\section{Appendix}

\section{LINES of INTERVIEW}

\section{PRELIMINARY QUESTIONS}
A. Gender (male, female)
B. Age (category :26-30, 31-35, 36-40, 41-45, 46-50, 51-55, 56-60, 60 \& older)
C. Experience in Counseling (In the general population, vulnerable groups)
D. Type and level of education (colleges, universities, Master, Doctorate)
E. Training in Counseling (seminars)

\section{LINES OF INTERVIEW}

1) According to your up to date work experience and education, how would you define the Advisory?

2) How would you determine the role of Executive Advisory? Do you think there is a differentiation on the role of Executive Advisory supporting socially vulnerable groups?

3) What are the beneficiaries' needs, which lead them to participate in a monitoring program of counseling?

4) What kind of importance do you attach to the opening meeting of the Consultative process? Please describe exactly what happens in accordance to its duration.

5) In your opinion, taking a professional decision in the consultative process must be coherent to or irrespective of the rest of his life benefited individual?

6) Within the role of Executive Advisory, do you believe that it includes the responsibility of making decisions for the benefit of the beneficiaries on the issues that concern them? How do you justify your answer?

7) Do you need further training / qualification in Counselling, in order to respond better to the task of supporting beneficiaries to undertake?

8) What are the reasons that make you want to get involved in further training in counseling?

9) What areas or what topics would you like to be included at program training / training in counselling, which will be of your interest to participate and which you think would improve your skills?

10) From your involvement in the Advisory Support to persons belonging to vulnerable social groups do you feel that there is a certain group - objective, which requires highly specialized knowledge and skills on the side of the Executive? If so, what group(s) ranks in this category?

11) Why the above group(s) requires the specialization of knowledge and skills for the Executives?

12) How far have you been able to diagnose and, subsequently, to meet the specific requirements of the beneficiaries of these groups?

13) Would you like to add or highlight more of your experience in counseling programs to this interview? 


\section{Copyright Disclaimer}

Copyright reserved by the author(s).

This article is an open-access article distributed under the terms and conditions of the Creative Commons Attribution license (http://creativecommons.org/licenses/by/3.0/). 